\title{
Low-Molecular-Weight Hydrophilic and Lipophilic Antioxidants in Nonmelanoma Skin Carcinomas and Adjacent Normal-Looking Skin
}

\author{
Konstantina Grammenandi ${ }^{a}$ Maria Kyriazi ${ }^{a}$ Alexandra Katsarou-Katsari ${ }^{\mathrm{b}}$ \\ Othon Papadopoulos $^{b}$ loanna Anastassopoulou ${ }^{c}$ Georgios T. Papaioannou ${ }^{a}$ \\ Alexandros Sagriotis $^{a}$ Michail Rallis ${ }^{a}$ Howard I. Maibach ${ }^{d}$ \\ ${ }^{a}$ Department of Pharmacy and b Dermatology Hospital of Andreas Syggros, School of Health Sciences, National and \\ Kapodistrian University of Athens, and ' Radiation Chemistry and Biospectroscopy, School of Chemical Engineering, \\ National Technical University of Athens, Athens, Greece; 'D Department of Dermatology, School of Medicine, \\ University of California, San Francisco, CA, USA
}

\author{
Keywords \\ Low-molecular-weight antioxidants · Skin cancer · Ascorbic \\ acid - Uric acid · $a$-Tocopherol · $\beta$-Carotene - Ubiquinol
}

\begin{abstract}
Low-molecular-weight antioxidants are some of the most efficient agents of the skin defense mechanism against environmental factors, such as cosmic rays, smoke, and pollutants. The total skin concentrations of hydrophilic ascorbic and uric acids, as well as lipophilic a-tocopherol, $\beta$-carotene, and ubiquinol-10 antioxidants were determined by an HPLCEC detector from 18 biopsies of human nonmelanoma skin carcinomas and 18 biopsies from skin areas adjacent to carcinomas. No significant differences in the concentrations of lipophilic antioxidants in both carcinomas and normal-looking skin areas adjacent to carcinomas were observed. On the contrary, ascorbic and uric acid concentrations were found to be 18 and $36 \%$ lower in carcinomas than in normal-looking skin areas, respectively. No statistical significance was observed between antioxidant concentrations and age, sex,
\end{abstract}

phototype, profession, site of tumor, frequency, and time of UV light exposure either. Accordingly the antioxidant concentrations in both cancerous skin and adjacent normallooking areas were found to be much higher than in normal skin, in contrast to literature data.

(c) 2017 S. Karger AG, Basel

\section{Introduction}

The skin is a highly metabolic tissue, which possesses the largest surface area of the body and acts as a protective barrier between the body and the harmful environmental pathogens [1]. It is directly exposed to various toxic environmental factors, which can generate reactive oxygen (ROS) and nitrogen species (RNS) such as ultraviolet light, ozone, cigarette smoke, pesticides, and pollutants [2-6]. Endogenous and environmental ROS and RNS are well known to be involved in aging as well as in inflammation, cancer, and other skin disorders $[7,8]$.

\section{KARGER}

E-Mail karger@karger.com

www.karger.com/spp
(C) 2017 S. Karger AG, Basel

$1660-5527 / 17 / 0296-0324 \$ 39.50 / 0$ 
The various defense mechanisms of the skin include enhanced physical stability against oxidative damage, efficient repair mechanisms and an antioxidant defense system [9]. The latter involves antioxidant enzymes and nonenzymatic antioxidants of low molecular weight (LMWA). LMWA include a number of compounds capable of directly preventing oxidative damage by reacting with free radicals or indirectly by restoring the damage or by stabilizing the redox potential of transition metals [10]. Towards enzymes the intrinsic LMWA are characterized by an increased penetration capacity, a wider spectrum of activity and the ability of regeneration by the cells $[7,9]$.

Skin cancer encompasses every ethnicity, socioeconomic and demographic cohort, geographic region and covers the entire lifespan [11-14]. In the last 3 decades the incident rates have increased by 5 -fold worldwide [15]. Among the nonmelanoma cancers, basal cell (BCC) and cutaneous squamous cell (cSCC) carcinomas are the most common skin cancers affecting globally an increased number of people $[15,16]$. The antioxidant levels of ascorbic acid, uric acid, ubiquinol-9, $\alpha$-tocopherol, and $\beta$-carotene of skin carcinomas could play an important role and significantly contribute to their pathogenesis and treatment. Furthermore, the concentration of the LMWA in the normal-appearing adjacent area is also very important and should be determined as it is the site where cancer most probably develops after surgical excision of the diseased area. Measures of other factors such as glucose and multidrug resistance transporters (unpubl. laboratory data) show much higher concentrations than in normal skin areas away from the cancer. Although there have been reports concerning LMWA levels in normal and UV-irradiated epidermis and dermis [17-20], there are no such studies for human nonmelanoma skin carcinomas.

The aim of this study is to determine the main hydrophilic and lipophilic LMWA concentrations in volunteer patients on nonmelanoma skin carcinomas and their adjacent normal-looking skin area, in order to better understand their role in the skin and the influence of cancer on their concentrations.

\section{Materials and Methods}

\section{Patients}

Thirty-six specimens of SCC or BCC and 36 specimens of the adjacent normal-looking skin area were obtained after surgical excision from selected volunteer patients of the Dermatology Hospital of Andreas Syggros, Athens, Greece. Eighteen specimens were
Table 1. Number of specimens by sex and age

\begin{tabular}{lcccll}
\hline \multicolumn{5}{c}{ Age groups } \\
\cline { 2 - 6 } & $30-40$ & $50-60$ & $60-70$ & $70-80$ & $>80$ \\
\hline $\begin{array}{l}\text { Hydrosoluble } \\
\text { Male }\end{array} \quad 1$ & 1 & 6 & 3 & 2 \\
$\begin{array}{l}\text { Female } \\
\text { Liposoluble antioxidants }\end{array}$ & 1 & 1 & 2 & 1 \\
$\begin{array}{l}\text { Male } \\
\text { Female }\end{array}$ & 1 & 1 & 4 & 2 & 3 \\
\hline
\end{tabular}

Age groups are indicated in years.

used for evaluating the hydrosoluble and 18 for the liposoluble antioxidants. The age range was $30-89$ years, 23 men and 13 women (Table 1). All the samples were frozen at $-80^{\circ} \mathrm{C}$ until their HPLC analysis.

Two of the 36 patients were categorized in phototype I-II, 14 patients in type II, 8 in type II-III and 12 in type III. The exact anatomical site of carcinomas was also recorded. Additional medical details based on their exposure/protection to/from natural or artificial UV light, time of exposure or ionizing radiation, living place, and occupation were recorded. All procedures were followed according to the Greek law of ethics for clinical research studies.

\section{Chemicals}

Ethanol, 2-propanol, methanol and hexane were HPLC grade from LAB-SCAN Ltd. (Dublin, Ireland). Water was HPLC grade purchased by Labconco Water Pro PS (USA), lithium perchlorate, sodium dodecylsulfate, $\mathrm{N}$-acetylcysteine, sodium chloride $(\mathrm{NaCl})$, sodium acetate $\left(\mathrm{CH}_{3} \mathrm{COONa}\right)$, sodium monobasic phosphate $\left(\mathrm{NaH}_{2} \mathrm{PO}_{4}\right)$, dihydrate disodium ethylenediamine tetraacetic acid $\left(\mathrm{Na}_{2}\right.$ EDTA $\left.\times 2 \mathrm{H}_{2} \mathrm{O}\right)$, tetraoctyl ammonium bromide $\left(\mathrm{C}_{32} \mathrm{H}_{68} \mathrm{NBr}\right)$, dodecyl trimethyl ammonium bromide $\left(\mathrm{C}_{15} \mathrm{H}_{34} \mathrm{NBr}\right)$, butyl hydroxyl toluene, ascorbic acid, uric acid and ubiquinone-10 were obtained from Sigma Chemical (St. Louis, MO, USA). Desferal and $\beta$-carotene were purchased from CibaGeigy, Athens, Greece, and BASF, Germany, respectively, and a-tocopherol was offered by Henkel, Germany.

\section{Extraction of Antioxidants}

Tissue samples were deeply frozen immediately after excision. Frozen tissues were accurately weighed, sectioned in very small pieces and transferred in 2 test tubes placed on dry ice.

\section{Ascorbic and Uric Acid Extraction}

Three milliliters of solution containing $90 \%$ methanol, $10 \%$ of $1 \mathrm{mM} \mathrm{Na} 2 \mathrm{EDTA} \times 2 \mathrm{H}_{2} \mathrm{O}$ in $\mathrm{H}_{2} \mathrm{O}, 100 \mu \mathrm{L}$ butyl hydroxyl toluene $\left(1 \mathrm{mg} / \mathrm{mL}\right.$ in ethanol), and $15 \mu \mathrm{L}$ Desferal $\left(1 \mathrm{mM}\right.$ in $\left.\mathrm{H}_{2} \mathrm{O}\right)$ were used to homogenize each sample of the skin. A Teflon homogenizer (Glas-Col, IN, USA) rotated by an appropriate transformed drill $(2,400 \mathrm{rpm}$, Black and Decker, UK) was used for $5 \mathrm{~min}$. The homogenate mixture was then transferred to a vial and centrifuged at $4,000 \mathrm{rpm}$, for $3 \mathrm{~min}$ at $4^{\circ} \mathrm{C}$. The supernatant was diluted (1:19) in an $\mathrm{H}_{2} \mathrm{O}$ /methanol solution 1:1. This solution was filtered and kept in storage at $-80^{\circ} \mathrm{C}$, until injection to the HPLC system. 


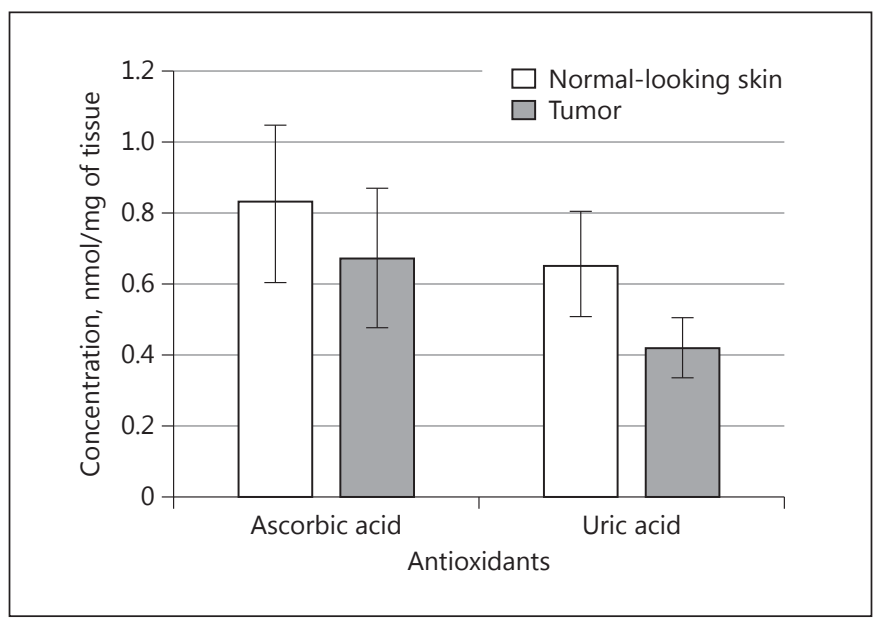

Fig. 1. Hydrophilic antioxidant concentration in normal-looking skin and tumor samples.

Vitamin E, $\beta$-Carotene, and Ubiquinol-10 Extraction

Each sample was added in a tube which contained $2 \mathrm{~mL}$ of a buffer ( $\mathrm{pH}$ 7.0) consisting of $\mathrm{NaCl} 130 \mathrm{mM}$ in $\mathrm{H}_{2} \mathrm{O}, \mathrm{Na}_{2}$ EDTA $\times$ $2 \mathrm{H}_{2} \mathrm{O}(1 \mathrm{mM})$, and $\mathrm{NaH}_{2} \mathrm{PO}_{4}(10 \mathrm{mM}), 50 \mu \mathrm{L}$ butyl hydroxyl toluene $(1 \mathrm{mg} / \mathrm{mL}$ in ethanol), and $1 \mathrm{~mL}$ sodium dodecylsulfate $(0.1 \mathrm{M})$. The sample was homogenized for $5 \mathrm{~min}$ as described above. Then, $2 \mathrm{~mL}$ of ethanol were added, and the mixture was sonicated and vortexed for $15 \mathrm{~s}$. Two milliliters of hexane were added followed by vigorous vortexing for $15 \mathrm{~s}$. The final mixture was centrifuged for $15 \mathrm{~min}$ at $500 \mathrm{rpm}$. Then, $1.5 \mathrm{~mL}$ of the hexane layer was transferred to a vial, and the solvent was evaporated. The residue was dissolved in $0.2 \mathrm{~mL}$ methanol, reagent alcohol (ethanol/2propanol 95/5) 1:1, vortexed and sonicated. Then it was filtered and kept in storage at $-80^{\circ} \mathrm{C}$, until injection to the HPLC system.

During both extraction procedures, the samples and solutions were kept on ice and in a dark room to prevent any oxidation from light.

\section{HPLC Analysis}

The high-performance liquid chromatographer consisted of an SP 8800 ternary pump (Spectra Physics, CA, USA), a 20- $\mu$ injection loop of Rheodyne (CA, USA), a $\mathrm{C}_{18}$ Hypersil Hyrurity ${ }^{\mathrm{TM}}$ Elite 5 - $\mu \mathrm{m}$ column " $4.6 \mathrm{~mm} \times 25 \mathrm{~cm}$ " for hydrophilic antioxidant analysis (Runcorn, UK), and a $\mathrm{C}_{18}$ Beckman Ultrasphere ODS $5-\mu \mathrm{m}$ reversed phase column " $4.6 \mathrm{~mm} \times 25 \mathrm{~cm}$ " for the lipophilic ones (CA, USA). The system was coupled with a Jasco 840-EC electrochemical detector (Tokyo, Japan).

For ascorbic and uric acid detection, the liquid phase consisted of 95:5 $\mathrm{H}_{2} \mathrm{O} /$ methanol 1:1 (v/v), sodium acetate $800 \mathrm{mM}$, tetraoctyl ammonium bromide $3.66 \mu \mathrm{M}$, dodecyl trimethyl ammonium bromide $200 \mu \mathrm{M}$ and dihydrate disodium ethylenediamine tetraacetic acid $(0.54 \mathrm{~mm})$. The $\mathrm{pH}$ was adjusted to 4.75 with acetic acid $(1 \mathrm{M})$.

For $\alpha$-tocopherol, ubiquinol-10 and $\beta$-carotene detection, the liquid phase consisted of the methanol/reagent alcohol (1:3.75) containing $0.06 \mathrm{M}$ lithium perchlorate, as electrolyte.

Quantitation was done using a standard curve equation in a range of $0.05-10 \mu \mathrm{M}$. Tests with standard fresh solutions were frequently injected during analysis.



Fig. 2. Lipophilic antioxidant concentration in normal-looking skin and tumor samples.

\section{Statistical Analysis}

The normality of data was checked using the Shapiro-Wilk test, by data histogram observation and $z$-values of skewness and kurtosis. The comparison of antioxidant concentrations of tumor towards adjacent normal skin was realized by the Wilcoxon test. Significance was accepted when $p<0.05$.

Based on visual observation of the histograms and the Q-Q plots, as well as the Shapiro-Wilk results, the concentration data do not follow normal distribution. Therefore, parametric methods (like 2-way ANOVA or $t$ test) are not applicable.

The aim of the comparisons was to explore the difference in the antioxidant levels between the 2 skin areas (normal-looking vs. cancerous) of each patient. Mixing together different types of data cannot obtain statistical results. Therefore, the right methodology is to apply a "paired" method, as is the Wilcoxon method.

In order to compare differences in antioxidant concentrations between men and women the Mann-Whitney U test was used because of the nonnormal distribution. It must be noticed that the lower number of women results from the fact that for ages over 60 years the risk factor for skin cancer is higher for men than for women.

\section{Results}

The evaluated hydrophilic and lipophilic antioxidant concentrations of both normal-looking adjacent and tumor skin samples are shown in Figures 1 and 2, respectively and are summarized in Table 2. $z$-values of skewness and kurtosis are greater than 1.96.

The significance values of the Wilcoxon test revealed a statistically significant difference between the hydrophilic antioxidant mean values of normal-looking skin and tumor samples ( $p=0.003$ for uric acid, $p=0.022$ for ascorbic acid). The mean ascorbic acid concentration is 
Table 2. Calculated antioxidant concentrations in tissues

\begin{tabular}{|c|c|c|c|c|}
\hline \multirow[t]{2}{*}{ Antioxidant } & \multicolumn{2}{|c|}{$\begin{array}{l}\text { Normal-looking skin concentration, } \\
\mathrm{nmol} / \mathrm{mg} \text { of skin tissue }\end{array}$} & \multicolumn{2}{|c|}{$\begin{array}{l}\text { Cancerous skin concentration, } \\
\mathrm{nmol} / \mathrm{mg} \text { of skin tissue }\end{array}$} \\
\hline & mean & SEM & mean & SEM \\
\hline Ascorbic acid & 0.82778 & 0.2214 & 0.67473 & 0.19749 \\
\hline Uric acid & 0.65549 & 0.14966 & 0.41822 & 0.085 \\
\hline a-Tocopherol & 0.00947 & 0.00264 & 0.00977 & 0.00214 \\
\hline Ubiquinol & 0.001 & 0.0003 & 0.00082 & 0.0002 \\
\hline$\beta$-Carotene & 0.00941 & 0.00266 & 0.00939 & 0.00219 \\
\hline
\end{tabular}

$18 \%$ higher in normal-looking skin than in tumor samples. Similarly, the mean uric acid concentration is $36 \%$ higher in normal-looking than in tumor samples. In contrast, no significant difference in measurements of mean values was observed for lipophilic antioxidants between normal-looking skin and tumor samples.

Table 2 shows that in healthy tissues the concentrations of hydrophilic antioxidants are 100 times greater than those of lipophilic antioxidants. Furthermore, the ubiquinol concentration is 10 times less than those of $\alpha$-tocopherol and $\beta$-carotene and shows a slight but not statistically significant reduction in cancerous tissues.

The Mann-Whitney U test shows no statistical difference between the 2 sexes $(p>0.05)$ for both lipophilic and hydrophilic antioxidants. The extrapolation of this observation is limited by the statistically small sample number, especially of women: 6 and 7 in the case of hydrophilic and lipophilic antioxidants, respectively, while for men it was 12 and 11 .

Table 1 shows that the critical age for BCC development in most cases is after 60 years (30-83.5\%), while in relatively young age groups $<50$ years there were only 2 $(2-5.5 \%)$ cases and between 50 and 60 years only 4 (4$11 \%)$. It is also obvious that the majority of the patients were males (23-64\%).

Thirty-two (32-89\%) out of 36 patients (36) showed the nonmelanoma skin cancer on the head, an area exposed to sunlight, and 1 on the calf. Only 3 of them were found in nonexposed areas (abdomen, chest, and tongue).

Thirty-three were BCC and 3 SCC.

Twenty-four (24-67\%) of the patients had fair skin and $12(12-33 \%)$ a darker white skin according to the Fitzpatrick classification.

Thirty (30-83\%) of them were frequently exposed to sunlight and most of them without any protection (20$55 \%)$ or using a hat (11-30.5\%).

Almost half of the patients lived in the Athens area $(19-53 \%)$ and half in the province (17-47\%).

Endogenous Antioxidants in

Nonmelanoma Skin Carcinomas

\section{Discussion}

The importance of skin LMWA is no doubt of great interest, since they are involved in skin defense systems. In order to evaluate the influence of cancer on LMWA levels of skin, we measured both hydrophilic and lipophilic nonenzymatic antioxidants in tumors and adjacent normal-looking skin, since these nonenzymatic antioxidants are suggested to be involved in oxidative damage prevention and there are no data about these closely anatomically situated regions. There are not many studies on human skin concerning concentrations in the adjacent normal-looking skin. Most of the existing studies on human skin are focused on enzymatic antioxidants, such as glutathione peroxidase or glutathione and superoxide dismutase; however, the mechanism of the antioxidant activation is not yet well understood [21-24].

From the data of Figure 1 a deficiency of hydrophilic antioxidants, both ascorbic and uric acids, is observed in cancerous areas compared with the healthy tissues. In order to explain the results we have to take into account all the components which are produced during carcinogenesis and its progression. It is well documented that during cancer, as well as in developing photoaging, a peroxidation of membrane lipids and phospholipids takes place stimulating the lipid metabolism [25]. These reactions lead to an increase in lipophilic environment. Using infrared spectroscopy, Tsakiris et al. [26] showed the increasing lipophilic environment in BCC and that the lipophilicity was higher in melanoma, while an increase in amyloid-like protein formation was also observed. The same findings were also observed in bone metastatic cancer [27]. Thus, by increasing the lipophilic environment in cancer skin areas, the solubility of hydrophilic antioxidants is decreased. On the other hand, skin DNA is also an important target of UV-skin interaction [28, 29], which attracts most of the endogenous hydrophilic antioxidants for its protection and replication. Since the local 
environment of DNA is mostly hydrophilic due to the sugar-phosphate chain, it requires mostly hydrophilic antagonists. From all ROS species superoxide radicals $\left(\mathrm{HO}_{2}\right.$, $\left.\mathrm{O}_{2}^{-}\right)$, both radicals, especially the anion $\left(\mathrm{O}_{2}^{-}\right)$, are longlived free radicals and can move longer distances affecting thus larger areas of the skin. Ascorbic acid is one of the most important hydrophilic protectors, which directly reacts with superoxide radicals $\left(\mathrm{HO}_{2}, \mathrm{O}_{2}\right)$ produced in the body [30] during oxidative stress, by inhibiting the radicals from reacting with important molecules of the skin. The affinity of ascorbic acid with $\mathrm{HO}_{2}$ is $10^{10} \mathrm{M}^{-1} \mathrm{~s}^{-1}$ and with their anion $\mathrm{O}_{2}^{-}$. is $10^{9} \mathrm{M}^{-1} \mathrm{~s}^{-1}$. These competition reactions between ascorbic and uric acid with ROS could cause their deficiency as we have calculated (Fig. 1). Furthermore, ascorbic acid, like glutathiols, reacts as hydrogen atom donor and maybe has been consumed to regenerate the damaged molecules, as well as the damaged vitamin E [31, 32]. Ascorbic acid deficiency in blood was also observed in patients with heart failure, and the deficiency was related to lipid peroxidation, while vitamin $\mathrm{E}$ did not change its concentration [33]. The deficiency of hydrophilic LMWA and dehydration were also observed in normal aging of the skin [34] supporting our suggestion that by decreasing the concentration of water in a cancer area decreases the solubility of hydrophilic antioxidants leading further to a decrease in their activity.

From Figure 2 it is not shown that cancer affects the concentrations of the lipophilic antioxidants in both examined areas. One of the mechanisms that stabilize the concentrations of lipophilic antioxidants is the regeneration by taking hydrogen atoms from thiols and vitamin $\mathrm{C}$ $[31,32]$. If that is really the case, the lipophilic LMWA should protect the skin from oxidative stress. In practice however, this is not observed and the cancer continues to develop, because the environment of the skin cancer area becomes more lipophilic due to lipid peroxidation and amyloid-like protein formation [26, 27].

It is known from neurodegenerative diseases, cardiovascular diseases and cancer that amyloid proteins are associated with protein misfolding and phospholipid aggregations, inducing cytotoxicity. From the concentrations of Figure 2 it seems that the lipophilic environment encircles the lipophilic LMWA ( $\alpha$-tocopherol, $\beta$-carotene, and ubiquinol) and prevents them from reacting as skin protectors. This suggestion is also supported by the ubiquinol concentrations. In particular, ubiquinol, because of the presence of $2 \mathrm{OH}$ groups, is also hydrophilic and acts as transmembrane factor preventing lipid peroxidation and propagation by transferring electrons to ROS, while its activity depends on its hydrophilicity [35]. The slight reduction of the ubiquinol concentration clearly shows its dependence on a hydrophobic environment, which also decreased due to membrane peroxidation leading to the prevention of ubiquinol to react as electron transfer compound in the recycling of ubiquinone.

Recently [36] in vitro experiments using human serum albumin at different concentrations of vitamins $\mathrm{E}$ and $\mathrm{D}$ showed that increasing the concentration of vitamin $\mathrm{E}$ decreases the percentage of the $\alpha$-helix and increases the $\beta$-sheet, suggesting that the increasing vitamin E concentrations influence the proteins' physiological structure [37]. These experiments reinforce our suggestion that the lipophilic environment, formed during the development of cancer, significantly reduces the action of lipophilic LMWA.

If we take into account that skin cancer is related to oxidative stress, the increased concentration of antioxidants will increase their competition activity with the produced free radicals leading to inhibition of cancer development. However, this activity of the lipophilic antioxidants has not been observed. On the other hand, ROS require water to be produced, which means that in a lipophilic environment their production should decrease. Therefore, it is assumed that the local accumulation of lipophilic LMWA maybe induces toxicity to skin tissues and that the protective mechanism of the body does not respond under these conditions. Kagan et al. [38] demonstrated that in accelerated cutaneous UV-induced aging the production of 8-oxo-2'-deoxyguanosine was independent from the vitamin E status. As demonstrated in our data, vitamin E appears to react mostly as enzyme regulator and less as free radical antagonist. Our results are also in accordance with those on superoxide dismutase and $\mathrm{Cu}, \mathrm{Zn}$-superoxide dismutase, where a reduction of their activity was found in various cancer tissues compared with normal tissues $[24,38,39]$. The differences in the behavior of enzymic and nonenzymic antioxidants in the epidermis and dermis were also noticed by other researchers $[18,19]$. The results of these studies suggested that the antioxidant concentrations in the epidermis are much higher than in the dermis [19] and were found to be much higher in human than in murine skin [18].

From the above experiments it seems that there are no significant differences in lipophilic antioxidant concentrations between cancerous and normal-looking skin adjacent to tumors. The same behavior was also observed in our study on the expression of transporters related to cancer in hairless mice with SCC, such as proteins MRP-1, PgP and GLUT-1 [40], which did not show any difference between the 2 studied regions. These data suggest that the 
Fig. 3. ImageJ analysis of normal skin (a), BCC (b), melanoma (c), and SCC (d). The red areas correspond to higher conductivity of the region, expressed with greater numbers of pixels. See online version for colors.

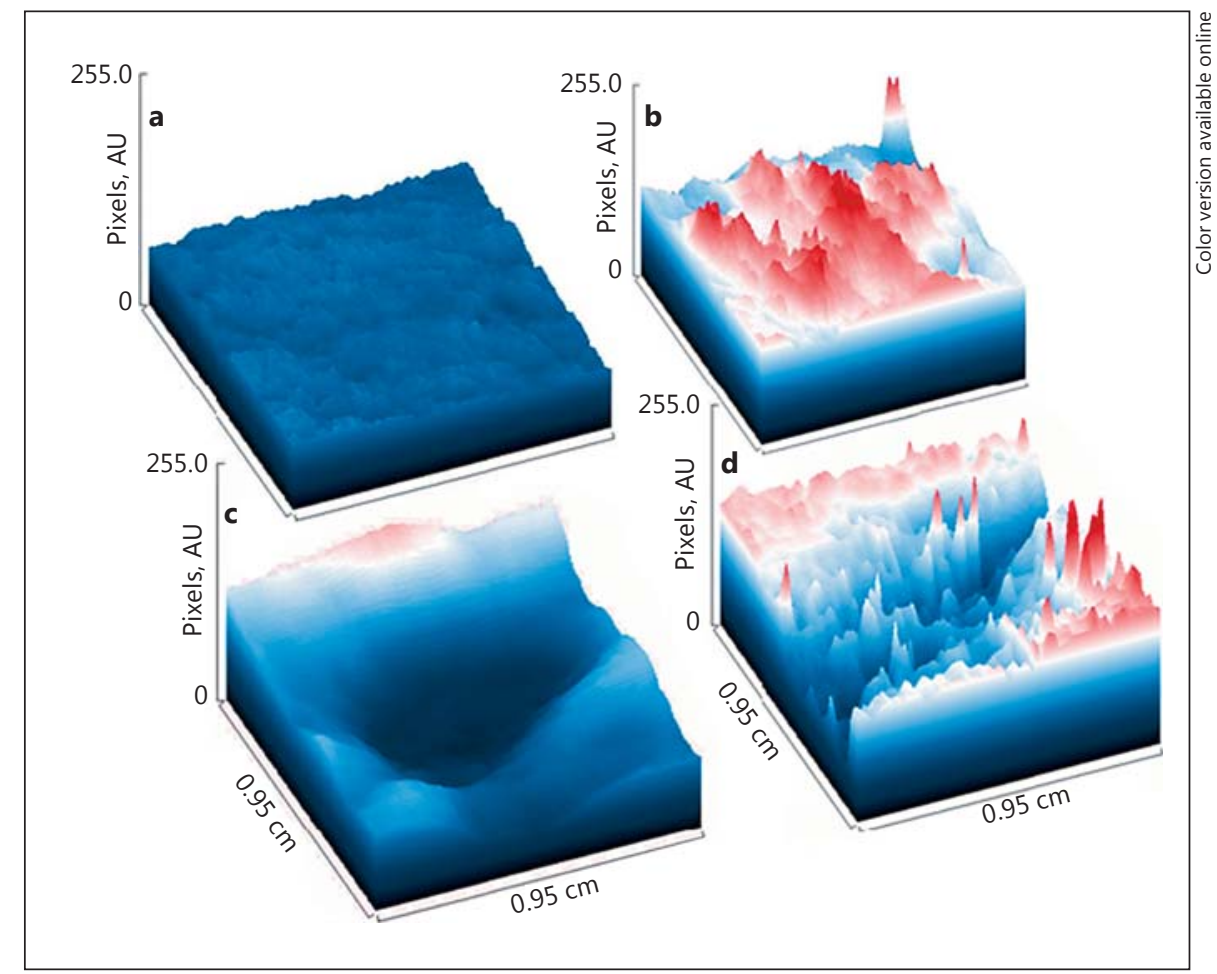

biochemical reactions which take place in skin during carcinogenesis could also affect the normal-looking adjacent skin.

Shindoetal.[19] determined lowerlevelsof $\alpha$-tocopherol in normal skin than in the corresponding tumor-adjacent skin and higher levels of ubiquinol, ascorbic and uric acids. Comparing these findings with our results, it is clear that the lipophilic environment due to the cancer progression plays a crucial role in the behavior of LMWA, since even ubiquinol, which shows a small hydrophilicity, decreases as is observed with ascorbic and uric acids. From the experimental data it becomes clear that oxidative stress is one of the pathways, which influence the LMWA concentrations and that the peroxidation membranes' lipids alter the structure and functions of other macromolecules. The biochemical alterations observed in many cases in areas adjacent to the cancer must be related to cancer stage and genomic instability. This fact could explain why after cancer excision the most probable area of cancer reappearance is the one adjacent to the cancer. Calculation of the antioxidant concentration may assist the surgeons to determine the exact surface area affected by the cancer.

Furthermore, using ImageJ surface analysis we analyzed the surface of the healthy region (Fig. 3a) and the regions of BCC (Fig. 3b), melanoma (Fig. 3c) and SCC
(Fig. 3d). As can be seen in Figure 3 there are significant differences between the normal and nonnormal skin.

Image J analysis shows epidermal differentiation between the types of cancer. In all patients the healthy area of the skin is homogeneous, while in the patients with BCC and SCC it shows the presence of minerals maybe from sodium, potassium, and calcium anions, originating from the damaged cells. Moreover, SCC shows a lesional skin barrier. It is also interesting to note that the melanoma region appears as a well, suggesting the creation of a strongly lipophilic environment. The alteration of lipid packing due to skin cancer was also observed using infrared spectroscopy $[26,27,41]$. These results are in agreement with the assumption that the lipophilic environment disturbs the behavior of LMWA.

For the better understanding of the molecular mechanisms of skin carcinogenesis, it is important to analyze more tissues from patients and if it is possible in different stages of cancer progression.

Concerning the epidemiological data obtained, even though the number of samples is small, all observations agree with the literature data. The higher observed incidence rate on patients aged $>60$ years as well as the greater prevalence in males than in females is in accordance with the data of a large epidemiological study in the USA 
which was realized in a total of 56,987 patients with BCC [42]. Similar evidence shows that exposure to UV light is the main environmental cause of BCC, since the area of the head which is exposed to sunlight is the most frequent anatomical site where BCC occurs [43, 44]. Likewise, populations with fair skin as well as mainly the phototypes II and III are the most touched by BCC [45].

It should be emphasized that although a nonparametric statistical method was used it was still possible to show significant differences, increasing thus the importance of the findings of this study. Whether there is indeed a statistical difference between the two sexes, further investigation with an increased number of women is required.

\section{Statement of Ethics}

All procedures were followed according to Helsinki rules and the Greek law of ethics for clinical research studies.

\section{Disclosure Statement}

The authors have no conflicts of interest to disclose.

\section{References}

1 Robinson PJ: Skin; in Wexler P (ed): Encyclopedia of Toxicology, ed 3. Reference Module in Biomedical Sciences. London, Academic Press, 2014, pp 283-309.

-2 Kammeyer A, Luiten RM: Oxidation events and skin aging. Ageing Res Rev 2015;21:1629.

3 Xu Y, Fisher GJ: Ultraviolet (UV) light irradiation induced signal transduction in skin photoaging. J Dermatol Sci Suppl 2005;1:S1S8.

-4 Krutmann J, Liu W, Li L, Pan X, Crawford M, Sore G, Seite S: Pollution and skin: from epidemiological and mechanistic studies to clinical implications. J Dermatol Sci 2014;76:163168.

$\checkmark 5$ Morita A: Tobacco smoke causes premature skin aging. J Dermatol Sci 2007;48:169-175.

-6 Yadav T, Mishra S, Das S, Aggarwal S, Rani V: Antecedents and natural prevention of environmental toxicants induced accelerated aging of skin. Environ Toxicol Phar 2015;39: 384-391.

7 Masaki H: Role of antioxidants in the skin: anti-aging effects. J Dermatol Sci 2010;58:8590.

-8 Ziech D, Franco R, Pappa A, Panayiotidis M: Reactive oxygen species (ROS)-induced genetic and epigenetic alterations in human carcinogenesis. Mutat Res 2011;711:167-173.

$>9$ Kohen R, Gati I: Skin low molecular weight antioxidants and their role in aging and in oxidative stress. Toxicology 2000;148:149-157.

$>10$ Kohen R: Skin antioxidants: their role in aging and in oxidative stress - new approaches for their evaluation. Biomed Pharmacother 1999;53:181-192.

11 Lazareth V: Management of non-melanoma skin cancer. Semin Oncol Nurs 2013;29:182194.
12 Steding-Jessen M, Birch-Johansen F, Jensen A, Schüz J, Kjaer SK, Dalton SO: Socioeconomic status and non-melanoma skin cancer: a nationwide cohort study of incidence and survival in Denmark. Cancer Epidemiol 2010; 34:689-695.

13 Rogers HW, Weinstock MA, Feldman SR, Coldiron BM: Incidence estimate of nonmelanoma skin cancer (keratinocyte carcinomas) in the US population, 2012. JAMA Dermatol 2015;151:1081-1086.

14 Lacy K, Alwan W: Skin cancer. Medicine 2013;41:402-405.

15 Leiter U, Eigentler T, Carbe C: Epidemiology of skin cancer. Adv Exp Med Biol 2014;810: 120-140.

16 Skin Cancer Foundation: Skin cancer facts. http://www.skincancer.org/skin-cancerinformation/skin-cancer-facts (accessed April 22, 2015).

17 Kohen R, Oron M, Zelkowicz A, Kanevsky E, Farfouri S, Wormser U: Low molecular weight antioxidants released from the skin's epidermal layers: an age dependent phenomenon in the rat. Exp Gerontol 2004;39:67-72.

$>18$ Shindo Y, Witt E, Packer L: Antioxidant defense mechanisms in murine epidermis and dermis and their response to ultraviolet light. J Invest Dermatol 1993;100:260-265.

19 Shindo Y, Witt E, Han D, Epstein W, Packer L: Enzymic and non-enzymic antioxidants in epidermis and dermis of human skin. J Invest Dermatol 1994;102:122-124.

20 Fuchs J, Weber S, Podda M, Groth N, Herrling T, Packer L, Kaufmann R: HPLC analysis of vitamin $\mathrm{E}$ isoforms in human epidermis: correlation with minimal erythemal dose and free radical scavenging activity. Free Radic Biol Med 2003;34:330-336.

21 Sander CS, Chang H, Salzmann S, et al: Photoaging is associated with protein oxidation in human skin in vivo. J Invest Dermatol 2002; 118:618-625.
22 Pandel R, Poljšak B, Godic A, Dahnane R: Skin photoaging and the role of antioxidants in its prevention. ISRN Dermatol 2013;2013: 930164.

23 Moysan A, Clement-Lacroix PM, Dubertret L, Morliere P: Effects of ultraviolet A and antioxidant defense in cultured fibroblasts and keratinocytes. Photodermatol Photoimmunol Photomed 1995;11:192-197.

-24 Morliere P, Moyysan A, Santus R, Huppe G, Maziere JC, Dubertret L: UVA induced lipid peroxidation in cultured human fibroblasts. Biochim Biophys Acta 1991;84:261-268.

25 Diaconu RE, Macarie AE, Orăsan R: Analysis of oxidative stress in sun-exposed and unexposed skin. HVM Bioflux 2014;6:153-157.

26 Tsakiris A, Dritsa V, Anastassopoulou J, Koui M, Theophanides T: An FT-IR spectroscopic study of basal cell carcinoma (BSS). Abstracts 6th Int Conf Oxidative Stress Skin Biol Med, Andros, August 2014.

27 Anastassopoulou J, Kyriakidou M, Kyriazis S, Dritsa V, Kormas T: Protein folding and cancer. Anticancer Res 2014;34:5806-5709.

28 Matsumura Y, Ananthaswamy HN: Toxic effects of ultraviolet radiation on skin. Toxicol Appl Pharmacol 2004;195:298-308.

29 Gaiba S, Tucci-Viegas VM, Franna LP, Lavaskovitsch F, Azevedo FLA, Moreas AAFS, Ferreira AT, Franna JP: Biological effects induced by ultraviolet radiation in human fibroblasts; in Schmid I (ed): Flow Cytometry - Recent Perspectives. Rijeka, InTech Publications, 2013, pp 439-456.

30 Von Sonntag C: The Chemical Basis of Radiation Biology. London, Taylor \& Francis, 1989.

-31 Oberley LW, Buettner GR: Role of superoxide dismutase in cancer a review. Cancer Res 1979;97:1141-1149. 
32 Packer JE, Slater TF, Wilson RI: Direct observation of a free radical interaction between vitamin E and vitamin C. Nature 1979;278:737738.

-33 Shindo Y, Witt E, Packer L: Antioxidant defence mechanisms in murine epidermis and dermis and their responses to ultraviolet light. J Invest Dermatol 1993;100:260-265.

-34 Keith M, Geranmayergan A, Sole MJ, Kurian $\mathrm{R}$, Robinson A, Jeejeebhoy KN: Increased oxidative stress in patients with congestive heart failure. J Am Coll Cardiol 1998;31: 1352-1356.

35 Kohen R, Gati I: Skin low molecular weight antioxidants and their role in aging and in oxidative stress. Toxicology 2000;148:149-157.

36 Abu Teir MM, Abu Awwad I, Darwish SM, Abu-Hadid MM: Study of the interaction of hydrophobic vitamins (vitamin $\mathrm{E}$ and vitamin D) with HAS using spectroscopic techniques. Int J Curr Res 2014;6:70537063.

- 37 James AM, Cochemé HM, Smith RA, Murphy MP: Interactions of mitochondria-targeted and untargeted ubiquinones with the mito- chondrial respiratory chain and reactive oxygen species. Implications for the use of exogenous ubiquinones as therapies and experimental tools. J Biol Chem 2005;280: 21295-21312.

38 Kagan VE, Kisin ER, Kawai K, Serinkan BF, Osipov AN, Serbinova EA, Wolinsky I, Shvedova AA: Toward mechanism-based antioxidant interventions: lessons from natural antioxidants. Ann NY Acad Sci 2002;959:188198.

39 Hamanaka H, Miyachi Y, Tzchibana T, Imamura S: Lowered $\mathrm{Cu}, \mathrm{Zn}$-superoxide dismutase activity in human malignant skin tumors J Invest Dermatol 1991;18:258-261.

40 Parthymos G: Study of Expression of Transporter Proteins MRP1, PgP, and GLUT1 on hairless mice nonmelanoma skin cancer tissues; MSc thesis, National and Kapodistrian University of Athens, Athens, 2005, pp 5761.

41 Zoschke C, Ulrich M, Sochorová M, Wolff C, Vávrová K, Ma N, Ulrich C, Schäfer-Korting M: The barrier function of organotypic non- melanoma skin cancer models, J Control Release 2016;233:10-18.

42 Gondenberg G, Karagiannis T, Blanche Palmer J, Lotya J, O'Neill C, Herrera V, Siegel DM: Incidence and prevalence of basal cell carcino$\mathrm{ma}$ (BCC) and locally advanced BCC (LABCC) in a large commercially insured population in the United States: a retrospective cohort study. J Am Acad Dermatol 2016;75:957-966.

43 Khalesi M, Whiteman DC, Tran B, Kimlin MG, Olsen CM, Neale RE: A meta-analysis of pigmentary characteristics, sun sensitivity, freckling and melanocytic nevi and risk of basal cell carcinoma of the skin. Cancer Epidemiol 2013;37:534-543.

44 Raasch B, Maclennan R, Wronski I, Robertson I: Body site specific incidence of basal and squamous cell carcinoma in an exposed population, Townsville, Australia. Mutat Res 1998;422:101-106.

45 Patrascu V, Stoica LE, Georgescu CV, Patru E: Histopathological and clinical-progressive profile in skin carcinomas: study on 1,688 cases. Rom J Morphol Embryol 2010;51:171-180. 